\title{
Universiteit
}

Leiden

The Netherlands

\section{Using CLIL to enhance pupils' experience of learning and raise attainment in German and health education: a teacher research project}

Mearns, T.L.

\section{Citation}

Mearns, T. L. (2011). Using CLIL to enhance pupils' experience of learning and raise attainment in German and health education: a teacher research project. The Language Learning Journal, 40(2), 175-192. doi:10.1080/09571736.2011.621212

Version: $\quad$ Not Applicable (or Unknown)

License: $\quad$ Leiden University Non-exclusive license

Downloaded from: https://hdl.handle.net/1887/44283

Note: To cite this publication please use the final published version (if applicable). 


\section{Using CLIL to enhance pupils' experience of learning and raise attainment in German and health education: a teacher research project}

\section{Tessa L. Mearns}

To cite this article: Tessa L. Mearns (2012) Using CLIL to enhance pupils' experience of learning and raise attainment in German and health education: a teacher research project, The Language Learning Journal, 40:2, 175-192, DOI: 10.1080/09571736.2011.621212

To link to this article: http://dx.doi.org/10.1080/09571736.2011.621212

曲 Published online: 21 Oct 2011.

Submit your article to this journal $[\pi$

山 Article views: 505

Q View related articles $\sqsubset$

Citing articles: 3 View citing articles ¿ 


\title{
Using CLIL to enhance pupils' experience of learning and raise attainment in German and health education: a teacher research project
}

\author{
Tessa L. Mearns* \\ Department of Education, University of Aberdeen, UK
}

\begin{abstract}
This paper describes and evaluates an action research project carried out by a teacher in an English comprehensive school, where a class of 13- to 14-year-olds was taught personal, social and health education and German through contentlanguage integrated learning (CLIL) over a six-week period. The purpose of the study was to explore how CLIL would influence both motivation and attainment by giving learners the opportunity (i) to experience language learning with a broader, more applied purpose; (ii) to experience success in TL interactions; and (iii) to use linguistic structures in a more 'natural' context. The findings of the study were mixed with regard to motivation, as pupils struggled to equate their continued lack of confidence after a short period of CLIL with their increased academic success. With regard to attainment, the most able pupils exceeded their previous achievements by at least one National Curriculum level, although little improvement was noted in the levels of the less able pupils. This could be attributed to the short time frame of the study, and the resulting lack of confidence referred to above. This research is also evidence of the developing role of practitioner-research in the academic community, the validity and importance of which is also discussed.
\end{abstract}

\section{Introduction and definition of CLIL}

CLIL or content-language integrated learning is a rapidly expanding concept in language learning in Europe (Smit 2008). It draws on immersion techniques prominent in Canada since the 1960s (Cummins 1998; Cook 2001a), but also on the broad range of approaches to bilingual teaching and learning that have existed across the world for centuries (Coyle 2007). Over recent years, CLIL as a concept has developed a range of different meanings (Lorenzo 2007; Seikkula-Leino 2007; Smit 2008), which can lead to the term being ambiguous. In this study, 'CLIL' is understood to be an approach to teaching and learning that employs a foreign language (FL) as the principle medium of instruction for a content-based subject. Key to the approach referred to here is that equal importance is attributed to the linguistic and the topic-based aspects of instruction (Marsh 2002). This reflects Lorenzo's (2007) view that effective topic-based teaching should strive to teach content as effectively as in a first language (L1) context, while not neglecting

*Email: t.1.mearns@abdn.ac.uk 
the linguistic achievement of learners. CLIL differs from immersion teaching, where the goal is for learners to become equally fluent in both the target language (TL) and their mother tongue (Seikkula-Leino 2007). The goal of CLIL is to produce competent and confident TL users, while at the same time teaching subject content. It is also worth noting that the form of CLIL employed in this project is what Clegg (2003: 89) would refer to as 'language led', in that it was carried out in a languages department rather than in a content subject department.

\section{The project}

The aim of this pilot project was to use CLIL to teach personal, social and health education (PSHE) in tandem with German throughout one six-week period to pupils aged 13 to 14 (Year 9, Key Stage 3) in an English secondary school. Evaluation of the project focused on (a) pupils' linguistic attainment, and (b) their motivation to learn the target language (TL).

The programme was developed by the teacher-researcher on the basis of advice and observations in published research, in particular Coyle's '4Cs framework' (Coyle 1999, 2006, 2007) which proposes that effective CLIL teaching and learning should integrate the four elements of 'content', 'cognition', 'communication' and 'culture': coverage of the subject matter ('content') should be combined with activities to nurture thinking skills ('cognition'), linguistic skills ('communication') and a sense of community and citizenship ('culture'). This is particularly appropriate in the context of the UK National Curriculum which places emphasis on meta-skills such as interaction and thinking skills. A preliminary attitude survey and existing PSHE materials (e.g. Hargreaves and Watts 2008) were also used in the development process. The project was evaluated qualitatively through a summative questionnaire and quantitatively through analysis of assessment data from before and after the project.

\section{The context}

The pilot programme focused on one class in a large 11-19 comprehensive school in England. The school specialises in modern foreign languages (MFL) and has a large and successful MFL department. All pupils learn French as their first foreign language from their first year at the school, and 93\% adopt German, Spanish or Latin as their second foreign language in their second year. All pupils continue study of at least one MFL in their exam years (Key Stage 4 ages 14-16), when they are allowed to select freely from those previously studied.

The class selected to be the subject of this study was a Year 9 group of 30 pupils aged 13 and 14, who had been learning German for nearly two years. The group was of relatively high ability, with the majority of pupils achieving National Curriculum Level 4-5 on the NC eight-point scale (roughly equivalent to Level A2 of the European Framework) in the assessment prior to the beginning of the study. ${ }^{1}$ Of the 29 pupils that responded to the preliminary questionnaire, a total of $22(76 \%)$ had chosen to continue with German as one of their exam (GCSE) subjects. This suggests that most of the class had a positive view of German prior to embarking on the CLIL project and this was broadly confirmed by the preliminary questionnaire (see below). 


\section{Ethical considerations}

The study was conducted after all data related to setting for exam classes had been collected and pupils had submitted their subject choices for the following year. Permission to carry out the study was sought from the relevant subject leaders, who were consulted on all aspects of planning. Pupils were given the right to withdraw from questionnaires, all of which were completed anonymously and individually in class time, under the supervision of the teacher-researcher. With regard to the content selected, any risk of compromising the quality of pupils' health education was mitigated in that the project was carried out at a stage when PSHE was not a statutory subject, nor was it formally timetabled for third year pupils.

\section{Teacher research}

The researcher in this case was also the pupils' German teacher. The role of teacherresearcher brought with it a number of advantages; in particular, the fact that the teacher-pupil relationship and basic classroom routines had been established prior to the start of the project. This meant that the pupils were generally willing to adjust to a new approach and to give honest and constructive feedback. As emphasised by Borg (2010) and Zeichner (2003), teacher action research such as this can offer a motivating break from routine for pupils, as well as empowering schools and teachers to take control of their own self-improvement agenda. Less positive aspects include the time constraints experienced by the teacher-researcher in trying to accomplish both roles effectively, and lack of opportunity for support from other researchers/academics, which would normally be available in the case of external research projects.

While there may be limitations to its empirical precision and generalisability, such teacher research is increasingly respected as a professional development tool (Borg 2010). As Goodnough (2010: 167) has said: 'the development of selfunderstanding about being a teacher is critical to learning how to teach'. Kemmis (2010) emphasises the role of practitioner research as a means to the practical end of improving practice in the immediate professional context, while Cochran-Smith and Lytle (2009) advocate inquiry as a normal 'stance' for education professionals, who they believe should be constantly and actively involved in educational reform. Carr (2007) has similarly argued that educational research should be seen as a "practical science' in the sense that it should directly inform practice rather than contributing to theory alone, providing teachers with access to systematically collected evidence of good practice that they can easily apply to their own work. Carr points out that larger-scale, theoretical research findings are often little trusted by teachers, who are aware of the very individual nature of their learners and of their teaching and learning situations. This supports Ebbutt's (1985) view that action research should be seen as a legitimate academic undertaking and means of communicating with a broader range of professional peers. Nevertheless, the limitations of such a smallscale study as this are inevitable, and are reviewed in a final section of this paper.

\section{Background}

\section{Linguistic attainment in CLIL}

It can be tempting in the early stages of teaching a foreign language to focus on short, individual words and phrases rather than on connected discourse. Yet 
teaching vocabulary through a focus on individual words, disconnected from one another and decontextualised, has been criticised as an artificial approach providing inadequate input for successful second language development (Krashen 1981; Krashen and Terrell 1983; Smith and Paterson 1998; Coyle 2007). It is now generally believed that language learning takes place more effectively if there are opportunities for interacting with 'meaningful input' (Krashen 1985; Ellis 2009) involving both explicit and implicit learning of vocabulary and grammatical structures. In this context, CLIL can be viewed as providing a potentially richer and more stimulating linguistic environment than the traditional language learning classroom where linguistic input is often very tightly restricted (Smith and Paterson 1998; Coyle 2007).

The positive impact of CLIL on linguistic development was observed by Coyle (2006) in a study of a CLIL programme in a UK secondary school, where she noted significant rises in pupils' linguistic attainment. Similarly, Seikkula-Leino (2007) reported that learners in CLIL classes in Finland had a significantly higher level of language than their peers in monolingual education, while Cummins (1998) observed that receptive (comprehension) skills reached near-native level in children taught through immersion programmes. The Nuffield Report on Language Education (Nuffield 2000) also observed improvements in attainment as a result of CLIL in the UK, citing the example of a school where a range of first year subjects were taught through the medium of MFL. In that school, improved attainment was particularly evident in boys, although other research has identified few differences between the performance of boys and girls in bilingual contexts (Seikkula-Leino 2007).

The literature on the subject of linguistic attainment is, however, not entirely positive. A number of studies have given rise to concerns that CLIL might have negative effects on the learning of both language and content, compared to conventional approaches (DeCourcy and Burston 2000; Master 2000; Day and Shapson 2001). With regard to content, Seikkula-Leino (2007: 336) has concluded that 'teaching in a pupil's mother tongue provides the pupil with more opportunities to reach maximum results'. Studies of French immersion programmes in Canada show that while learners in these programmes generally develop excellent TL receptive skills, their ability to produce grammatically accurate language does not develop to the same extent (Harley et al. 1991; Cummins 1998). In this respect, however, Lorenzo's (2007) proposal is helpful: he argues that productive language skills can be developed more effectively if a CLIL curriculum is carefully planned and delivered to combine sufficient focus-on-form activities alongside the teaching and learning of the subject content.

\section{Motivation and possible selves}

It has been observed that young people in the UK can appear particularly reluctant to learn foreign languages (Hawkins 2005). A suggested reason for such demotivation is the lack of ostensible purpose, such as the need to speak the language in order to find employment or communicate in a language other than English when abroad (Stern 1983; Chambers 1999; Evans and Fisher 2005; Graddol 2006; Mearns 2006). CLIL has been shown to counteract this apparent lack of drive in young people learning languages in a number of different ways (Coyle 2007; Smit 2008). Pupils learning through CLIL have reported increased motivation to attend language lessons, an improved sense of achievement and a view that their learning is relevant to the world outside of the language classroom (Coyle 2006). For some 
pupils, the TL in CLIL classrooms is employed as a means of conveying information and opinion on topics that they find genuinely interesting (QCA 2007a). In Finland, it has been observed that learners of CLIL appear to be more motivated to learn both the language and the content of lessons, and that they attribute the cause of their raised motivation to success rather than task facility (Seikkula-Leino 2007). In the latter study, however, it was also noted that the same pupils had lower selfesteem as language learners than their monolingual peers, in spite of their increased motivation to learn, a point we return to later in this paper.

But how can we explain this increased motivation? The answer could lie in the 'realism' of the CLIL classroom. A relatively recent theory of L2 learning motivation is Dörnyei's (2005, 2009) work on the 'L2 Motivational Self System'. Dörnyei has turned to the psychological concept of multiple selves and, more specifically, 'possible' or 'future' selves (Markus and Nurius 1986) in order to investigate more fully the learner's inclination towards or against learning a second or foreign language. According to this concept, a great deal of human motivation is driven not so much by extrinsic goals as by the vivid visualisation of what kind of person we hope, expect or feel we should become if our goals were to be achieved. Dörnyei argues, for example, that the greater the 'perceived plausibility of the ideal (future) self', the stronger the influence on motivation. In this way, if a learner is given the chance to experience success in using the target language to achieve a 'real' task, even if this is a learning task as is typically the case in CLIL, then they are more likely to be able to visualise themselves using the language effectively in the future, and their motivation for language learning is likely to be enhanced.

\section{Planning the project \\ Preliminary questionnaire}

Prior to the beginning of the project, the class completed an anonymous online questionnaire asking their opinions regarding German lessons and language learning up until that point in the year (see Appendix 1.1). This was both in order to aid curriculum planning and to provide a baseline comparison for the later summative questionnaire. Twenty-nine pupils responded to the questionnaire. Question 3 asked pupils to say what they thought of German lessons on a five-point Likert scale where one $=$ 'rubbish' and five $=$ 'great'. Question 4 provided lists of topics studied from which pupils selected the 'best' and the 'worst', while Question 5 asked pupils to indicate 'the most important things about learning a language' and provided eight alternatives, plus an 'other' option, from which pupils could select as many as they wished.

In answer to Question 3, 41\% pupils of pupils gave German lessons a positive score of at least four (i.e. 'quite good' or 'great'). Twenty-seven per cent, however, rated German lessons at one or two ('rubbish' or 'not very good') with $31 \%$ giving a neutral 'three' score ('OK'). Pupils' preferences concerning topics (Question 4) were extremely varied, and it was not possible to identify any particular consensus among members of the class. With regard to aspects of language learning (Question 5), $53 \%$ of pupils selected 'speaking the language' as most important, followed by 'understanding the language' (47\%) and 'communication' (35\%). The items viewed as least important were 'learning grammar' $(12 \%)$ and 'writing in the language' $(12 \%)$. Pupils' view of German lessons prior to the beginning of the project could therefore be characterised as broadly positive, although a significant number were 
unenthusiastic. Using languages for immediate communication appeared to be the priority for most pupils in their language learning, while the methodical tasks of writing and learning grammar were viewed as less important. To reflect the findings of preliminary questionnaire, a large number of communication-based activities were incorporated into lessons, although the less popular aspects of language learning, such as grammar, were not omitted entirely from the syllabus. Evidence suggests that it is important that grammar be learned through CLIL, just as it would be through 'traditional' language teaching (Lorenzo 2007), in order to avoid a decline in linguistic accuracy and a purely 'focus on meaning' curriculum (Cummins 1998; Swain 2000; Pica 2002; Coyle 2007).

\section{Selection of content}

Personal, social and health education (PSHE) was chosen as the content for this project due to the teacher-researcher's interest and experience in this area and because of the apparent lack of previous studies published on this particular subject combination. Furthermore, PSHE is a subject area which focuses more on the processes of learning than on traditional examination outcomes (QCA 2007b), and thus it was felt that there was little risk of the research process impacting negatively on pupils' overall academic achievement, measured in terms of their examination results.

Within the existing PSHE curriculum, the theme of healthy lifestyles was chosen as the focus. This was convenient as parallels can be drawn between this topic and those routinely covered in the MFL syllabus, such as food and drink, sports and fitness. A challenge in selecting the content to be covered was that pupils with a relatively low level of language might be expected to perform tasks on a high cognitive level. At the same time, as the class included a large number of generally high-performing pupils, it was important to keep all learners engaged in the content by ensuring that it was sufficiently demanding cognitively. Learners would thus need to be provided with appropriate scaffolding to allow them to access the language required to complete the activities, with differentiation for less able members of the class. These issues were addressed through the assignment of mixed-ability groups, mixing word-based and image-based activities (see for example those in Lin and Mackay 2004) and providing learners with word-banks and writing or speaking frames.

\section{Development of the unit of work}

The six-week unit of work was developed through consultation with the leaders of the departments concerned (MFL, German and PSHE) and with reference to Coyle's (1999, 2007) '4Cs' framework and the findings of the preliminary survey. The resulting proposal was then approved by the subject leaders. The planned activities favoured group or paired work and thinking skills activities, reflecting published recommendations for the inclusion of pupil-centred learning in CLIL/immersion programme design (Cummins 1998; Coyle 2000). However, 'traditional' language learning resources such as vocabulary lists, writing and speaking frames and explanation of grammar, were not excluded completely. For example, when introducing the theme of fitness, it seemed natural to expose pupils to the expression 'um...zu' ('in order to...') and to consolidate work on modal verbs. This was an 
important consideration from the perspective of gaining the confidence of the MFL department that pupils' linguistic level would not be adversely affected by CLIL and in remaining faithful to the doctrine of not neglecting content for the sake of language or vice-versa (Eurydice 2006; Coyle 2006; Lorenzo 2007).

While the intention of this project was to increase TL interaction in the classroom, it was at no time stipulated that interaction was to occur entirely in the TL. While research has shown optimal TL use to aid the language learning process, this does not necessarily imply that exclusive use of the TL necessarily nurtures the best TL users (Cook 2001b). Nor is it a requisite of CLIL that all interaction should be in the TL: learners must also acquire cross-lingual and metalinguistic skills (Cummins 1998; Coyle 2007), for example through the use of code-switching, translation and other bilingual activities. In this project, for example, one activity involved pupils gathering information from English language resources and using dictionaries and word banks to construct a summary in the TL. Another activity involved drawing comparisons between British and German public information websites. Assessment instructions were issued in both languages to avoid misinterpretation and enable more independent preparation and the assessment criteria were written only in English for ease of comprehension and use. ${ }^{2}$

\section{Evaluation of the project}

\section{Assessment}

The assessment completed by pupils at the end of the six weeks was designed to evaluate their progress in MFL and their attainment in PSHE, for which they had no previous recorded level. The assessment task involved pupils working in friendship groups to produce a presentation on an aspect of health. The format for this task was based on an activity used earlier in the unit, such that it was not an entirely new concept for pupils. Preparation for the assessment was done almost entirely without teacher support and pupils were invited to use whichever visual aids they deemed appropriate.

The assessment criteria for content focused both on the outcome and the process of the assessment task. They took into account the quality of the final presentation and also the collaborative group work required to reach that outcome, as recommended by Coyle in her 'Toolkit' for designing a CLIL curriculum (Coyle 2006). As noted earlier, the language assessment was undertaken using the UK's National Curriculum level descriptors for MFL (QCA 2007a), which are entirely language-based (not dependent on specific vocabulary or content) and were familiar to pupils. The class was issued with a summary of both the MFL and PSHE criteria (both in English) alongside the instructions for the task. A final level for both the content and the language was issued to individual pupils by the teacher, but presentations were also peer-marked using the same criteria.

\section{Summative pupil survey}

Following their final assessment, pupils were asked to complete a summative questionnaire evaluating their experience of CLIL (Appendix 1.2). This questionnaire contained multiple-choice, Likert scale and open questions, allowing for a mixture of quantitative and qualitative data. Its purpose was to assess the extent to which pupils 
felt that CLIL had affected their learning and their experience of learning German and PSHE. Due to the timing of the CLIL project (at the end of the summer term), a number of pupils were absent on the day of the questionnaire, leading to a low response-rate. The final number of respondents was 16 out of a possible $26 .^{3}$

\section{Findings}

\section{Attainment}

\section{Results}

The results of the assessment at the end of the CLIL programme were generally positive. As can be seen from Figure 1, there was a general improvement in the levels of linguistic performance by pupils between April and July, with the median and mean each rising by one level ( $5 \mathrm{~b}$ to $6 \mathrm{~b}$ and $5 \mathrm{c}$ to $6 \mathrm{c}$ respectively) by the July assessment. These data show the class's highest level rising from $6 \mathrm{a}$ in April's assessment ${ }^{4}$ to $8 \mathrm{c}$ in July's presentations, which is an increase of four sub-levels in the space of one half-term.

However, while the highest level in the class rose significantly, the lowest did not. Four pupils achieved the class's lowest level of $4 \mathrm{c}$ in July, compared with five in April, suggesting very little improvement among the lower-achieving members of the class. It is true that the total number of pupils to achieve Level 4 in July was significantly lower than in April (five in July, as opposed to thirteen in April), but this does not detract from the fact that, for a small number of pupils, the CLIL pilot programme appears to have had little effect on their linguistic attainment, or indeed, may have diminished it.

In a qualitative sense, the assessment presentations were of mixed merit. Some groups rose to the challenge of working autonomously and prepared lengthy monologues to accompany their visual resources, while other groups merely read out the (not always accurate) bullet points on their PowerPoint slides. The lowest-quality presentation was given by an all-female group, while the presentation of the highest quality came from boys.

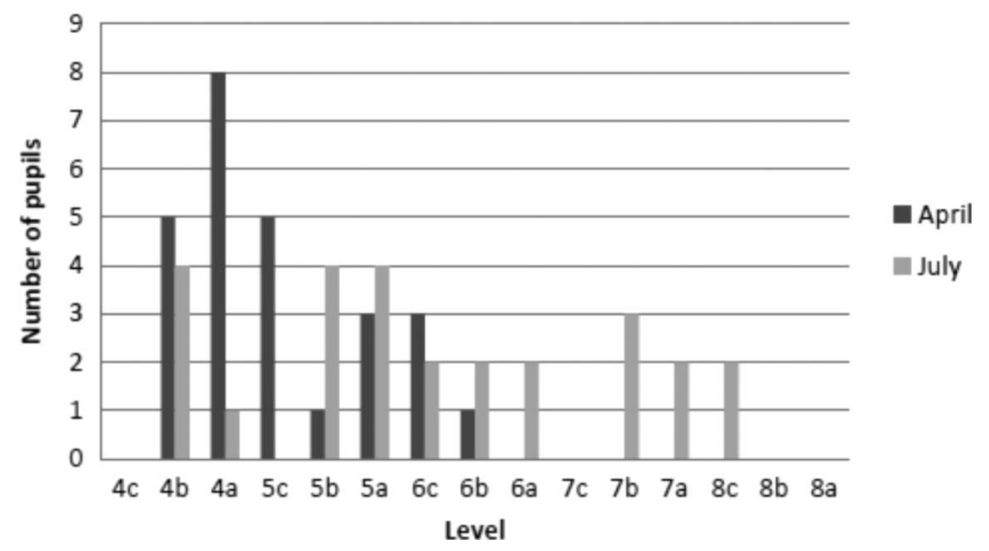

Figure 1. Results in April assessment compared to July CLIL assessment. 


\section{Discussion}

From the assessment results, it appears that the CLIL programme helped pupils even those who appeared to struggle with the assessment task - to achieve a higher linguistic level than in their previous assessment. This could be due to pupils' higher motivation in relation to the CLIL learning and assessment, and/or it could also reflect the richer linguistic learning environment that CLIL approaches seem to provide. As one pupil wrote in feedback regarding the assessment: 'I got to use a much wider range of vocabulary and skills and as a result my level has gone from $5 \mathrm{c}$ to $7 \mathrm{a} / 8 \mathrm{c}$ '. Significant improvements such as this run counter to Seikkula-Leino's (2007) observation that CLIL leads to no significant difference in average attainment in a class, but can depress the number of high-achievers.

However, in this pilot programme, CLIL appeared not to help the lowerachievers. This runs counter to Coyle's (2006) research and Simpson's (ALL 2008) experience of CLIL, which suggest: (a) that CLIL is particularly appealing to lowerability pupils; and (b) that CLIL is an effective means of teaching mixed-ability groups. There was little evidence here of increased confidence in lower-ability pupils. Smit (2008) acknowledges the risk of weaker pupils being 'overburdened' by the task of learning content through a FL and as noted above, Seikkula-Leino (2007) observes that self-esteem in CLIL learners can tend to be lower than for learners in conventional classes.

\section{Motivation}

\section{Results}

Pupils' responses on the summative questionnaire relating to motivation were mixed. Question 2 asked pupils to indicate their general level of enjoyment of the CLIL programme using a Likert scale from one ('rubbish') to five ('great'). Comparison with the responses to the similar Question 3 on the preliminary questionnaire suggested an increase in pupils' levels of reported enjoyment. As can be seen from Table 1, none of the respondents to the summative questionnaire rated their enjoyment at one ('rubbish'), and only one pupil gave a response of two ('not very good'). This compares with $28 \%$ (8 pupils out of 29) who gave scores of one or two in the preliminary questionnaire. There was also an increase in the proportion of pupils scoring the German course at four or five. However, caution is necessary in interpreting these results as the numbers responding to the summative questionnaire were significantly lower than those for the preliminary questionnaire.

The responses to Questions 7-10 of the summative questionnaire are shown in Table 2. Pupils were allowed to choose more than one option. The highest number of

Table 1. Pupils' overall assessment of German course pre- and post-CLIL.

\begin{tabular}{lcccr}
\hline Score & $\begin{array}{c}\text { Preliminary } N=29 \\
\text { Question } 3\end{array}$ & $\%$ & $\begin{array}{c}\text { Summative } N=16 \\
\text { Question 2 }\end{array}$ & $\%$ \\
\hline 1-2: 'Rubbish'/'not very good' & 8 & 28 & 1 & 6 \\
3: 'OK' & 9 & 31 & 4 & 25 \\
4-5: 'Quite good'/'great' & 12 & 41 & 10 & 63 \\
No response & 0 & 0 & 1 & 6 \\
\hline
\end{tabular}


Table 2. Enjoyment and difficulty of aspects of CLIL course.

\begin{tabular}{lllcc}
\hline Aspect & $\begin{array}{c}\text { Most } \\
\text { difficult }\end{array}$ & $\begin{array}{c}\text { Least } \\
\text { difficult }\end{array}$ & $\begin{array}{c}\text { Most } \\
\text { enjoyable }\end{array}$ & $\begin{array}{c}\text { Least } \\
\text { enjoyable }\end{array}$ \\
\hline Learning new vocabulary & $3(19 \%)$ & $5(30 \%)$ & $3(19 \%)$ & $3(19 \%)$ \\
Grammar & $8(50 \%)$ & $1(6 \%)$ & $0(0 \%)$ & $9(56 \%)$ \\
Speaking in class & $1(6 \%)$ & $1(6 \%)$ & $0(0 \%)$ & $2(13 \%)$ \\
Speaking in front of the class & $4(25 \%)$ & $1(6 \%)$ & $1(6 \%)$ & $6(38 \%)$ \\
Writing & $2(13 \%)$ & $4(25 \%)$ & $1(6 \%)$ & $6(38 \%)$ \\
Discussing difficult subjects & $1(6 \%)$ & $1(6 \%)$ & $1(6 \%)$ & $1(6 \%)$ \\
Working in groups & $2(13 \%)$ & $6(38 \%)$ & $11(69 \%)$ & $0(0 \%)$ \\
Preparing for assessment & $0(0 \%)$ & $2(13 \%)$ & $3(19 \%)$ & $2(13 \%)$ \\
Nothing & $1(6 \%)$ & $0(0 \%)$ & $0(0 \%)$ & $0(0 \%)$ \\
\hline
\end{tabular}

pupils (eight or $50 \%$ ) claimed to have found 'Grammar' most difficult. Only four respondents $(25 \%)$ chose 'Speaking in front of the class' as a 'most difficult' element of the project, and no pupil chose it exclusively. The element that pupils rated as 'easiest' was 'Working in groups' (38\%). Responses to Questions 9 and 10 concerning enjoyment reflected to some extent perceived levels of difficulty: 11 respondents $(69 \%)$ said that they had enjoyed 'Working in groups', while nine $(56 \%)$ reported that 'Grammar' was least enjoyable.

Despite their increase in attainment at the end of the CLIL course (see Figure 1 and above), pupils were non-committal in judging their own progress. In answer to Question 12, where pupils were asked to indicate the extent to which they felt they had made progress, $62 \%$ of respondents (10) gave a neutral rating of three on the five-point scale. Similarly, when asked to say how they felt about doing the presentation assessment task, $50 \%$ of pupils chose a rating of three, with the remaining responses falling on either side in equal numbers.

\section{Discussion}

Despite the limited scale of the evaluation, there appeared to be some indication that pupils' enjoyment of German lessons during the CLIL project increased. This would corroborate the positive results found in Coyle's study of CLIL in British schools (Coyle 2006; Eurydice 2006) which suggest that CLIL can be an enjoyable and motivating means of teaching and learning. Also apparent from the summative questionnaire, however, was some evidence of pupils' lack of confidence in their own progress, despite the demonstrable improvements in attainment grades discussed earlier. This could be seen as running counter to the common view that achievement and motivation are closely linked (Rivers 1964; Bandura, Adams and Beyer 1977; Ajzen 1988; Bandura 1993), and that experience of success increases the tangibility of the ideal L2 self. Instead, these data chime with the findings of Seikkula-Leino (2007), who noted that, while CLIL pupils' level of language was significantly higher than that of their monolingual counterparts, their perception of their own linguistic ability was more negative and self-critical. This may well be because the linguistic tasks in which CLIL learners are required to engage are experienced as more challenging, though there was no evidence in pupils' comments on the summative questionnaire to support this view. This disparity between apparent progress, as indicated by formal assessment, and pupils' own lack of perception of progress, 
might also suggest that they were uncertain of the validity of the assessment. A significant proportion of the class tended to rate 'Speaking in front of the class' as 'difficult' and 'not enjoyable', which might reflect this uncertainty. It could be that pupils found the demands of CLIL and the assessment task particularly challenging, although views of the presentation assessment itself tended to be neutral. Some pupils did struggle to work collaboratively with other members of their group and the presentations involved a great deal of independent preparation in a short period of time, which may have discouraged some members of the class.

Furthermore, the short time-scale of the entire project left little time to examine topics in depth and may have caused some pupils to feel overwhelmed at having to present to the class. Thus, rather than having the opportunity to 'experience success', pupils may have felt that they were being stretched too far. In terms of the L2 Motivational Self System, this situation works against Dörnyei's criterion for 'harmony between the ideal and ought selves' (Dörnyei 2009: 18). Some pupils may have felt that they were expected to perform at a level higher than what they realistically considered to be their ability. In this sense, the assessment task may have weakened pupils' image of their possible L2 self, rather than strengthening it. In this respect, pupils' reports of finding grammar the most difficult aspect of the unit were surprising considering that the teacher had made a conscious effort to limit explicit coverage of this area. It could be that 'Grammar' was considered as a catch-all term by pupils to indicate concerns about accurate target language use.

\section{Areas for development}

The pilot project reported here was necessarily limited in its scope and duration. However, it offered the opportunity for the teacher-researcher to explore how CLIL might be implemented in her class context, and what challenges would need to be addressed in future developments. The outcomes of the project were broadly positive, suggesting that a CLIL approach could have a positive impact on linguistic attainment and motivation, and certainly did not appear to have any significantly negative impact on pupils' learning. The following are suggestions for improvements that might be undertaken in future CLIL projects, based on the results of this investigation.

\section{Scope of the project}

Much of the previous research into CLIL projects has been more longitudinal, often spanning an academic year or more (Thomas and Collier 2002; Seikkula-Leino 2007). A number of difficulties encountered when planning and carrying out this action research were related to the short time-scale under which it was completed, which allowed little time for either the teacher or the pupils to become properly accustomed to the routines of the CLIL classroom. Previous research has documented time-constraints as being a possible cause of an increased proportion of teacher-centred activities and closed questioning in CLIL classrooms (Coyle 2007) and this can clearly limit the advantages that the CLIL approach has to offer. The short time-scale may also explain pupils' non-committal view of their otherwise demonstrable progress. It is important now to collect further evidence from longer implementations of CLIL to assess longer-term impact on motivation and linguistic attainment, and in particular, explore how to boost learners' 
confidence in their own language skills as this seems to be key to sustaining motivation and high achievement.

Furthermore, it is important to trial CLIL approaches with a wider range of students (the current pilot focused on just one class) including groups of different abilities and backgrounds, in order to explore further the suggestion from the present project that less able pupils benefit less from CLIL than those of higher ability. A potentially useful approach might involve all teachers in a modern foreign languages department collaborating in trialling CLIL, thus creating a 'consortium of research' (Kemmis 2010; NTRP 2010) across languages, classes and teachers.

\section{Identity and motivation in CLIL}

Two assumptions have been made in this paper with regard to Dörnyei's L2 Motivational Self System. Firstly, while research has suggested a link between future selves and learning motivation in general (Oyserman, Terry and Bybee 2002, 2006; Yowell 2002; Pizzolato 2006) there has at the time of writing been little published research evidence of the same effect in language learning specifically. Secondly, there is no direct evidence to support the assumption that CLIL will necessarily make a positive contribution to the development of the image of the L2 future self in the manner suggested here. A promising area for future research would therefore be to evaluate the validity of these assumptions. This might take the form of a traditional-style study of the motivational levels of CLIL and non-CLIL learners, coupled with an exploration of their sense of future L2 self. There might also be room for action research into the direct influence of an intervention aimed at developing all six areas of the L2 Motivational Self System in a group of language learners, in a similar vein to research carried out among at-risk youth in the context of avoiding school dropout (Oyserman, Terry and Bybee 2002).

\section{Students-as-researchers}

A key element of this research was that it was carried out by a teacher in the context of her own practice. This may add an element of authenticity and practicality to the findings, and will hopefully provide inspiration to other practitioners who wish to conduct their own school-based research. There is now also a growing movement in favour of 'participatory action research' (PAR) in which not only teachers but also their pupils take an active role in research conducted within their own school or learning environment. Through participation in a research process, pupils may experience a particularly stimulating context for learning; they can develop a greater sense of empowerment, feel listened-to in their learning context, build stronger relationships with their teachers and help their (teacher-) co-researchers gain access to a quality of data not necessarily available to them from an 'outsider' standpoint (Atweh and Burton 1995; Fielding 2004; Bland and Atweh 2007; Gunter and Thomson 2007; Leitch et al. 2007; Roberts and Nash 2009). In the context of CLIL research, pupil-researchers could be involved in a number of ways, ranging from consultation on data collection methods, ethics, curriculum content or teaching and learning methods, to acting as full-blown researchers, designing research tool and collecting and analysing data from their peers with limited adult support. 


\section{Conclusions}

This paper has reported on action research project focusing on evaluating the impact of a short CLIL programme in a UK secondary school where PSHE was taught through the medium of German. The evaluation by means of pupil questionnaires and analysis of assessment outcomes gave mixed results, though a number of indicators were generally positive. With regard to motivation, the majority of pupils appeared to appreciate the opportunity to learn German in a different context and this had a motivating effect for many, although not all, members of the group. From the perspective of attainment, the average grade in the class rose by approximately one National Curriculum level, and high-attainment pupils in particular had the opportunity to excel and to perform at a level not open to them in previous assessments. However, while the assessment task seemed to allow pupils to display improvement in their language skills, it did not appear to give pupils the same sense of confidence in their achievement reported by many of the subjects of Coyle's (2006) research. Other research has shown this to be less surprising than might first be thought (Seikkula-Leino 2007). This pilot project set out to try to explore the impact of CLIL on motivation, using Dörnyei's Motivational Self System, but further research is clearly needed to investigate this in more depth.

\section{Notes}

1. The presentation task was assessed using the UK National Curriculum (NC) levels employed in England, Wales and Northern Ireland to measure the progress of pupils up to the age of 14. The scales range from Level 1 (lowest) to Level 8 (highest) with sub-levels ranging from ' $c$ ' (lowest) to 'a' (highest) to allow for more differentiation within each level. Guidelines state that pupils should reach Level 2 by age 7, Level 4 by age 11 and Level 5 or 6 by age 14. For modern foreign languages (MFL), which are not yet taught consistently across all primary schools, pupils starting languages at secondary school are expected to achieve Level 1 by age 12, with higher-attaining pupils generally reaching Level 5 or 6 by age 14. According to CILT (2011), NC Levels 4-6 are equivalent to Common European Framework Level A2. For the detailed NC levels descriptors for MFL, see http://curriculum.qcda.gov.uk/key-stages-3-and-4/subjects/key-stage-3/modern-foreignlanguages/Level-descriptions/index.aspx.

2. The detailed scheme of work developed for the pilot CLIL programme, together with detailed assessment sheets, etc, can be obtained from the author.

3. There were inevitable small changes in class composition which meant that the number of pupils who completed the CLIL programme was slightly lower than the number who completed the preliminary questionnaire.

4. The April assessment (set by the modern languages department) comprised reading, listening, speaking and writing components. The reading and listening elements were comprehension tests based on short texts or audio tracks, with questions and answers in English. The speaking and writing tests both involved the reproduction by heart of a pre-prepared text. The highest level achievable in the assessment was National Curriculum Level 6.

\section{References}

Ajzen, I. 1988. Attitudes, Personality and Behavior. Chicago, IL: Dorsey Press.

ALL (Association for Language Learning). 2008. Linking French and geography - the Earth's structure, tectonic activity, volcanic formation and eruption. Subject Specific Support for the New Secondary Curriculum. Leicester, UK: Association for Language Learning.

Atweh, B. and L. Burton. 1995. Students as researchers: rationale and critique. British Educational Research Journal 21, no. 5: 561-75.

Bandura, A. 1993. Perceived self-efficacy in cognitive development and functioning. Educational Psychologist 28, no. 2: 117-48. 
Bandura, A., N.E. Adams and J. Beyer. 1977. Cognitive processes mediating behavioral change. Journal of Personality and Social Psychology 35, no. 3: 125-39.

Bland, D. and B. Atweh. 2007. Students as researchers: engaging students' voices in PAR. Educational Action Research 15, no. 3: 337-49.

Borg, S. 2010. Language teacher research engagement. Language Teaching 43, no. 4: 391-429.

Carr, W. 2007. Educational research as a practical science. International Journal of Research and Method in Education 30, no. 3: 271-86.

Chambers, G.N. 1999. Motivating Language Learners. Clevedon, UK: Multilingual Matters.

Clegg, J. 2003. The Lingue E Scienze Project: some outcomes. L'uso veicolare della lingua straniera in apprendimenti non linguistic. Centro Diffusione Comunitaire Quaderni 6.

Cochran-Smith, M. and S. Lytle. 2009. Inquiry as Stance: Practitioner Research for the Next Generation. New York: Teachers College Press.

Cook, V.J. 2001a. Second Language Learning and Language Teaching. London: Arnold.

Cook, V.J. 2001b. Using the first language in the classroom. Canadian Modern Language Review 57, no. 3: 402-23.

Coyle, D. 1999. Theory and planning for effective classrooms: supporting students in content and language integrated learning contexts. In Learning Through a Foreign Language: Models, Methods and Outcomes, ed. J. Masih, 46-62. London: CILT.

Coyle, D. 2000. Meeting the challenge: developing the 3Cs curriculum. In New Perspectives on Teaching and Learning Modern Languages, ed. S. Green, 158-82. Clevedon, UK: Multilingual Matters.

Coyle, D. 2006. Content and language integrated learning: motivating learners and teachers. Scottish Languages Review 13, online. http://www.librarything.com/work/9865383/book/ 59330614.

Coyle, D. 2007. Content and language integrated learning: towards a connected research agenda for CLIL pedagogies. International Journal of Bilingual Education and Bilingualism 10, no. 5: 543-62.

Cummins, J. 1998. Immersion education for the millennium: what have we learned from 30 years of research on second language immersion? In Learning through Two Languages: Research and Practice. Second Katoh Gakuen International Symposium on Immersion and Bilingual Education, ed. M.R. Childs and R.M. Boswick, 34-4. Katoh Gakuen, Japan.

Day, M. and S.T. Shapson. 2001. Integrating formal and functional approaches to language teaching in French immersion: an experimental study. Language Learning 51, supplement 1: 47-80.

DeCourcy, M. and M. Burston. 2000. Learning mathematics through French in Australia. Language and Education 14, no. 2: 79-95.

Dörnyei, Z. 2005. The Psychology of the Language Learner. Individual Differences in Second Language Acquisition. Mahwah, NJ: Lawrence Erlbaum.

Dörnyei, Z. 2009. The L2 motivational self system. In Motivation, Language Identity and the L2 Self, ed. Z. Dörnyei and E. Ushioda, 9-42. Bristol, UK: Multilingual Matters.

Ebbutt, D. 1985. Educational action research: some general concerns and specific quibbles. In Issues in Educational Research, ed. R. Burgess, 152-76. Lewes, UK: Falmer Press.

Ellis, R. 2009. A reader responds to Guilloteaux and Dornyei's "Motivating Language Learners: A Classroom-Oriented Investigation of the Effects of Motivational Strategies on Student Motivation". TESOL Quarterly 43, no. 1: 105-9.

Eurydice. 2006. Content and Language Integrated Learning (CLIL) at School in Europe. Brussels: Eurydice.

Evans, M. and L. Fisher. 2005. Measuring gains in pupils' foreign language competence as a result of participation in a school exchange visit: the case of Y9 pupils at three comprehensive schools in the UK. Language Teaching Research 9, no. 2: 173-92.

Fielding, M. 2004. Transformative approaches to student voice: theoretical underpinnings, recalcitrant realities. British Educational Research Journal 30, no. 2: 295-311.

Goodnough, K. 2010. The role of action research in transforming teacher identity: modes of belonging and ecological perspectives. Educational Action Research 18, no. 2: 167-82.

Graddol, D. 2006. English Next. London: The British Council.

Gunter, H. and P. Thomson. 2007. But, where are the children? Management in Education 21, no. 1: $23-8$.

Hargreaves, P. and L. Watts. 2008. Just for a Laugh. Durham, UK: Durham County Council. 
Harley, B., P. Allen, J. Cummins and M. Swain. 1991. The Development of Second Language Proficiency. Cambridge: Cambridge University Press.

Hawkins, E. 2005. Out of this nettle, drop-out, we pluck this flower, opportunity: rethinking the school foreign language apprenticeship. The Language Learning Journal 32: 4-17.

Kemmis, S. 2010. What is to be done? The place of action research. Educational Action Research 18, no. 4: 417-27.

Krashen, S. 1981. Second Language Acquisition and Second Language Learning. Oxford: Pergamon Press.

Krashen, S. 1985. The Input Hypothesis: Issues and Implications. London: Longman.

Krashen, S.D. and T.D. Terrell. 1983. The Natural Approach: Language Acquisition in the Classroom. Oxford: Pergamon Press.

Leitch, R., J. Gardner, S. Mitchell, L. Lundy, O. Odena, D. Galanouli and P. Clough. 2007. Consulting pupils in assessment for learning classrooms: the twists and turns of working with students as co-researchers. Educational Action Research 15, no.3: 459-78.

Lin, M. and C. Mackay. 2004. Thinking Through Modern Foreign Languages. London: Optimus Education.

Lorenzo, F. 2007. An analytical framework of language integration in L2 content-based courses: the European dimension. Language and Education 21, no. 6: 502-14.

Markus, H.R. and P. Nurius. 1986. Possible selves. American Psychologist 41: 954-69.

Marsh, D. 2002. CLIL/EMILE - The European Dimension: Actions, Trends and Foresight Potential Public Services Contract DG EAC. Brussels: European Commission.

Master, P. 2000. Grammar in content-based instruction. In Content-based College ESL Instruction, ed. L. Kasper, 93-106. Hillsdale, NJ: Erlbaum.

Mearns, T. 2006. 'I don't need French': factors that influence intrinsic and extrinsic motivation in secondary school language learners. Unpublished masters diss., University of Newcastle.

NTRP (National Teacher Research Panel). 2010. Research and Evidence Informed Practice in Schools: An Illustration and Discussion of the Key Issues. http://www.standards.desf.gov. uk/ntrp/ourvalues/reipis/.

Nuffield. 2000. Languages: the Next Generation. London: The Nuffield Foundation.

Oyserman, D., D. Bybee and K. Terry. 2006. Possible selves and academic outcomes: how and when possible selves impel action. Journal of Personality and Social Psychology 91, no. 1: 188-204.

Oyserman, D., K. Terry and D. Bybee. 2002. A possible selves intervention to enhance school involvement. Journal of Adolescence 25, no. 3: 313-26.

Pica, T. 2002. Subject matter content: how does it assist the interactional and linguistic needs of classroom language learners? The Modern Language Journal 85: 1-19.

Pizzolato, J.E. 2006. Achieving college student possible selves: navigating the space between commitment and achievement of long-term identity goals. Cultural Diversity and Ethnic Minority Psychology 12, no. 1: 57-69.

QCA (Qualifications and Curriculum Authority). 2007a. Modern foreign languages: programme of study for Key Stage 3 and attainment targets. The National Curriculum 2007. London: Qualifications and Curriculum Authority.

QCA (Qualifications and Curriculum Authority). 2007b. PSHE: personal wellbeing programme of study (non-statutory) for Key Stage 3. The National Curriculum 2007. London: Qualifications and Curriculum Authority.

Rivers, W.M. 1964. The Psychologist and the Foreign-Language Teacher. Chicago, IL: The University of Chicago Press.

Roberts, A. and J. Nash. 2009. Enabling students to participate in school improvement through a Students as Researchers programme. Improving Schools 12, no. 2: $174-$ 87.

Seikkula-Leino, J. 2007. CLIL learning: achievement levels and affective factors. Language and Education 21, no. 4: 328-41.

Smit, U. 2008. The AILA research network - CLIL and immersion classrooms: applied linguistic perspectives. Language Teaching 41, no. 2: 295-8.

Smith, J. and F. Paterson. 1998. Positively Bilingual: Classroom Strategies to Promote the Achievement of Bilingual Learners. Nottingham, UK: Nottingham Education Authority. 
Stern, H.H. 1983. Fundamental Concepts of Language Teaching. Oxford: Oxford University Press.

Swain, M. 2000. The output hypothesis and beyond: mediating acquisition through collaborative dialogue. In Sociocultural Theory and Second Language Learning, ed. J. Lantolf, 97-114. Oxford: Oxford University Press.

Thomas, W.P. and V.P. Collier. 2002. A National Study of School Effectiveness for Language Minority Students' Long-Term Academic Achievement. http://crede.berkeley.edu/research/ llaa/1.1pdfs/1.1_02purpose.pdf.

Yowell, C.M. 2002. Dreams of the future: the pursuit of education and career possible selves among ninth grade Latino youth. Applied Developmental Science 6, no. 2: 62-72.

Zeichner, K. 2003. Teacher research as professional development for p-12 educators in the US. Educational Action Research 11, no. 2: 301-25. 


\section{Appendix 1}

\subsection{Preliminary questionnaire}

\section{What do you think of German?}

I'd like to know what you think of German and German lessons. This is part of some research I am conducting for the German department.

Make sure you read all of the questions carefully and give the correct number of answers for each one.

\section{ALL ANSWERS ARE ANONYMOUS - PLEASE BE HONEST!}

1. Are you male or female?

2. What language(s) are you taking next year? (Please tick as many as apply)

$\begin{array}{lll}\text { French } & \text { German } & \text { Spanish Latin } \\ \text { Mandarin } & \text { Russian } & \text { Other (please give details) }\end{array}$

3. What have you thought of German lessons this year? (Please select a number from 1-5)
(1) 'rubbish'
(2) 'not very good'
(3) ' $\mathrm{OK}$ '
(4) 'quite good'
(5) 'great'

4(a) In your opinion, what has been the best topic we've done in German this year? (Please tick one)

$\begin{array}{llll}\text { Hobbies } & \text { Clothes } & \text { School uniform } & \text { Shopping } \\ \text { Food } & \text { Local area } & \text { Media (e.g. cinema) } & \text { Other (Please say what) }\end{array}$

4(b) In your opinion, what has been the worst topic we've done in German this year? (Please tick one)
Hobbies
Clothes
School uniform
Shopping
Food Local area
Media (e.g. cinema)
Other (Please say what)

5. What do you think are the most important things about learning a language? (Tick as many as you like)
Learning grammar
Communicating
Learning vocabulary
Speaking the language
Reading in the language
Writing in the language
Learning about culture
Understanding the language
Other (Please say what)

\subsection{Summative questionnaire}

\section{Summative questionnaire: PSHE/German CLIL project}

A few weeks ago, you completed a survey about what you thought of German lessons. Since then we have been learning German in a different way and I would like to know how you have felt about it.

REMEMBER, THIS SURVEY IS ANONYMOUS - you must answer honestly!

1. Are you male or female?

2. How much have you enjoyed German lessons this half-term?
'rubbish'(1)
(3)
(4)
(5) 'great'

3. What level did you get for your health presentation?
a. content
b. language

4. Is your language level higher or lower than after your last assessment? 
5. How much do you feel you have learned about the following topics?

Fitness

'nothing at all' (1)

(2)

(3)

(4)

(5) 'a lot'

Healthy eating

'nothing at all' (1)

(2)

(3)

(4)

(5) 'a lot'

Drugs

'nothing at all' (1)

(3)

(4)

(5) 'a lot'

6. How difficult have you found the work in German this half-term?

'really easy' (1)

(2)

(3)

(4)

(5) 'impossible'

7. What have you found most difficult?

Learning new vocabulary

Writing

Grammar

Speaking in class

Speaking in front of the class

Nothing

Discussing difficult subjects

Working in groups

Preparing for assessment

8. What have you found least difficult?

Learning new vocabulary

Grammar

Speaking in class

Speaking in front of the class

Nothing

\section{Writing}

Discussing difficult subjects

Working in groups

Preparing for assessment

9. What have you enjoyed the most?

Learning new vocabulary

Grammar

Speaking in class

Speaking in front of the class

Nothing

\section{Writing}

Discussing difficult subjects

Working in groups

Preparing for assessment

10. What have you enjoyed the least?

Learning new vocabulary

Grammar

Speaking in class

Speaking in front of the class

Nothing

\section{Writing}

Discussing difficult subjects

Working in groups

Preparing for assessment

11. How did you feel about doing the assessment presentation?

'very negative' (1)

(3)

(4)

(5) 'very positive'

12. How much do you feel your German has improved this half-term?

'not at all' (1) (2)

(3)

(4)

(5) 'a lot'

Do you have any other comments about the work we have done on health in German? 